\title{
Integrated Mode Design and Analysis of Networked Learning and PBL Teaching
}

\author{
Ke Yu ${ }^{1, a}$, Xiaoping $Z \mathrm{hu}^{2, \mathrm{~b}}$, Yihua $\mathrm{Du}^{1, \mathrm{c},{ }^{*}}$ \\ ${ }^{1}$ The affiliated Hospital of Luzhou Medical College, Luzhou 646000, China \\ ${ }^{2}$ Graduate college, Luzhou Medical College, Luzhou 646000, China \\ a524497168@qq.com, ${ }^{b}$ zxp95900@163.com, ${ }^{\text {c} 13608282389 @ v i p .163 . c o m ~}$
}

Keywords: Network, PBL, Teaching mode.

\begin{abstract}
In recent years, the networked learning is a kind of new learning style with the development of Internet technology. The new learning style of networked teaching has been widely attention and development. PBL teaching mode is a problem-oriented teaching methods and teaching methods based on students as the core. In this paper, the networked learning and PBL teaching mode are analyzed and discussed, and the integrated mode is carried out design and analysis.
\end{abstract}

\section{Introduction}

With the development of computer science and technology in recent years, networked learning, and this emerging learning style also gradually came into being. Networked learning as an emerging learning style, which receive wide attention in society. The networked learning is to establish a teaching platform via the Internet, which makes the students learn through network, it is a kind of new learning mode. Networked learning is very different from the traditional teaching mode; network teaching has great randomness and freedom. At present, networked learning has significant influence and role in the field of adult education, enterprises training, and higher education and so on, and the popularity of the networked education also has been gradually expanded.

\section{The analysis of the networked learning}

The current science and technology level develop rapidly, the Internet level has grown by leaps and bounds, based on the existing knowledge system, in the support of the Internet technology, multimedia technology and other emerging technology, a kind of advanced teaching methods, and network teaching is formed. Networked learning has bright prospects, around the world; the rapid development of networked learning also illustrates the issue. Networked learning integrated the world advanced learning resources, learning conditions, teaching resources are rich and varied in network teaching, and advance with times. Excellent learning environment and resources can make educate accept more new and comprehensive education in great extent, understand learning content in-depth, promote the digestion and understanding of knowledge. Real-time interactivity of network teaching makes students can real-time interact with educators, reduce the influence on teaching by time factor and geographical factors, reduce the teaching time and difficulty, increase the learning efficiency. The networked learning is the organic combination of computer network technology and the traditional education, its development and advance with the further development of science and technology and constantly improves and popularizes.

\subsection{The characteristics of networked learning}

Networked learning mode provides a highly rich knowledge database. In the environment of networked learning, a large number of data technical documentation, corresponding teaching programs, news and other resources makes the educate obtain more education content. The networked learning is an open, shared learning environment, the internal learning materials can be for all people to learn and use, and provides a place for communication, everyone can express their ideas and opinions and contribute their knowledge material at the same time; it can be for more people to 
learn and share. According to their own needs and views, participating learners can select suitable learning materials for their own in the network; take the appropriate method to study. The instant update of information is also important factor of networked learning, each learner in network platform can access the latest learning materials and information, it has great significance for immediacy of information; ensure the advanced nature of the learning materials.

The information expression way of networked learning education platform are diverse, the development of multimedia technology provides a number of information of video, images, text form for learners to learn. A variety of data form can improve the learners' interest; increase the receptivity, promote the absorption of knowledge. The application of network resources for learners is one of the core content of networked teaching, networked teaching resources is not confined to the teachers' curriculum resources, as well as the electronic library and other teaching resources. Depth and breadth of teaching resources has great change compared to traditional teaching methods, to strengthen the use of the Internet education resources has a very important significance to networked learning.

The real-time interactive features of networked learning can make real-time communication between students and teachers, it has great promoting role in understanding of the problem and the absorption of knowledge. The communication between teachers and students can by voice video dialogue, electronic message board, email and so on; the diversification of communication mode is easy for communication between the parties. And between learners and learners can communicate, show their own opinions and views, the education resource sharing, promote learning recognition has a great promoting role. Network learning platform build their own question-answering system, through the computer automatic answering questions, teachers answering questions, communication and discussion answering questions and son, guide learning process of students correctly, improve the learning quality of student.

Another big characteristic of networked learning is in any time and any place, in the traditional teaching mode, it need to be face-to-face communication between educators and learners, and has great limit on time and place. The networked learning mode reduce the limitation of time and place, learners and teachers can realize the communication and exchanges through the network platform, and learners' learning resources completely can be obtained in the network platform, learners can arrange study time according to their own situation at any time, improve their learning efficiency. Networked learning model also has high customizability, educators and learners can use and choose different teaching models to study, and make autonomous learning according to their own time condition, content arrangement need to be studied.

Networked teaching mode is convenient for the teacher to student's management work, because the teaching in network environment, when students in learning, all kinds of data, such as knowledge views, learning efficiency, the answer effect of topic answering questions condition and other specific data, according to the specific situation, the teacher can carry on the management and personalized guidance for each student. Compared with traditional education mode, it is more scientific and objective. It has great benefits to improve students' learning knowledge ability, adjust the students' knowledge structure.

\subsection{The related problems of networked learning}

Because the networked learning has considerable freedom and liberty, so it has great requirement for students' self-discipline. When receiving network teaching, really pay attention to the content of the networked teaching is important to improve the quality of networked teaching quality. Networked teaching has certain disadvantages for students' management, teachers need to work more, and carry out effective management and learning distribution for students in network learning. To strengthen the guide of students and arouse the learning enthusiasm of students, and make students better integrate the networked learning. In the interaction of networked learning, assigning students with similar level students to discuss and communicate, it can improve the students' learning efficiency. At the same time, summarize and sort out the learning content, improve the quality of teaching resources. There is large amount of information in the network platform, at the same time information content is more complex. If students in learning without good guidance, it is easy to result in information 
obtaining too much and too mixed, ignore the important content, a waste of time. In networked learning process, because students lack self-control, students only pursue speed and quantity in the learning, for actual mastery level the knowledge is greatly neglected, and interested in the content that doesn't have to do with learning in the network, so as to reduce the learning efficiency and learning quality.

In networked teaching, some problems in students' learning achievement evaluation still exist. Because the networked teaching development time is shorter, the experience is relatively insufficient, evaluation way is relatively single. The students' levels that use networked teaching are different, if make same evaluation method to the user, so it will inevitably produce not appropriate part.

\section{The analysis of the PBL teaching}

PBL teaching is problem-based teaching way, its English abbreviation is the problem- -based learning, the fundamental purpose of PBL teaching method is to develop students' creative ability, developing students potential. PBL teaching take students as the core, carry out teaching activity surrounding students, and it has very big change compared with the traditional teaching mode. PBL teaching has created a new type, high initiative learning atmosphere. It lets the student can express their views and opinions easily and actively, it is convenient for students to communicate and discuss with others, and deepen the understanding of knowledge. At the same time, in the learning process, the problems students faced are easier to expose, constantly find and solve new problems, and improve the master degree of knowledge. When using PBL mode for teaching, for the students' expression and analysis ability, logical reasoning ability and so on has the very big enhancement, enhance the students' learning ability, improve the teaching quality and teaching effect.

\subsection{The definition of PBL teaching}

PBL teaching is started in the 1950's, it was invented by American medical education experts Barrows, it was first applied in medical comprehensive education courses, in the field of medical education, the advantage of the PBL teaching method have been constantly demonstrated, and this new teaching method has also been widely promoted and popularized. PBL teaching method is a new teaching way; the most direct translation is teaching methods based on the problems. PBL as a new teaching method and the past is very different from traditional teaching methods, PBL teaching method is mainly based on students' learning, change teacher's teaching as the core in the traditional education ago, in the learning content, take the initiative to give priority to students' knowledge required, emphasize the students autonomously learning and solve the problem, this has a lot of help to improve students' learning ability and problem-solving ability. PBL teaching method takes question as the foundation in clinical medical science curriculum, the students as the main body, the teacher as study guide, and mainly consists of group. The learning curriculum combine the task with higher authenticity, the learning is designed to the real, complicated situations, strive for learners' mutual cooperation and the independent analysis to solve the problem. Thereby, students' practical ability and problem-solving ability are improved, and teachers make directional guidance in the learning, to stimulate students' initiative and enthusiasm. In the modern teaching, emphasize improving the students' learning ability and the ability to acquire knowledge. PBL teaching method is a kind of new teaching methods can improve students' learning ability.

\subsection{The positive effect PBL teaching mode bring}

Change the position of the students and the way of thinking. In PBL learning, students are not only the simple participants, but the main body in the whole learning environment, students autonomously discuss and analyze in learning, strengthen students' responsibility, reduce the passive access to knowledge, increase the ability to solve problems actively, improve the students' interest.

Enhance students' ability to solve problems. In the traditional teaching mode, the traditional teaching mode separate theoretical study from practice condition to teach, make students' practical ability and practical problem-solving ability is not strong. The improvement of traditional teaching mode is limited for students' clinical problem-solving ability, pays too much attention to research theoretical problem, and cannot make the students obtain improvement of due ability effect. Then 
PBL mode through specific questions propose by giving students an active problem-solving environment, improve students' practical ability, lets the student better combine theoretical knowledge and practice. For students in clinical practice in the future, this is an important experience acquisition process. And the improvement of students' learning ability also are not ignored, improve the learning ability is fundamental significance to solve clinical problems in the future.

Improve the students' cooperative ability. In the process of PBL teaching, the students should play their own initiative and participation. When solving the problem, pay attention to strengthen cooperation with team members, enhance the team cooperation, enhance collaboration and communication ability, this also has a big significance to improve the students' ability.

Students' critical thinking obtain development. In the process of the traditional teaching, because students' learning is passive to accept the teacher's teaching knowledge, it cause too rigid to accept knowledge. This cause the students' thinking ability, insight level of the problem is difficult to improve and develop. PBL mode focuses on the student' self-active thinking analysis, therefore, it has a considerable help to improve students' innovation and strengthen initiative learning.

\subsection{Requirement of the PBL teaching on participants}

PBL teaching mode has a lot of requirements for teachers' quality and teaching ability, the teacher not only have enough knowledge base professional ability and logical thinking ability in the professional field, , but also requires teaching skills with high level and management organization ability. In the course, teacher must be good at stimulate the students' learning interest, inspire students' potential, control teaching rhythm well, causes the student to obtain better learning effect.

PBL teaching also need the students' active participation, from the proposition of subject, actively prepare and check data, actively communicate and collaborate with other classmates, embody the spirit of mutual cooperation. In the early stage of the classroom, carry out most preparatory work, focus on classroom preparation, improve consciousness and achieve learning effect. Students should start from the traditional learning style change into active learning; improve their initiative in knowledge acquisition.

\subsection{The thinking design of PBL teaching}

The concrete structure PBL teaching mode: teachers propose and specify the question before class, and then students independently find information to solve problem according to situation, and according to the condition, group discussion is made to get results, at last, teachers do explanation and summary. When teachers make preparation before class, they need to refer to the related information of teaching course, combining with the actual example reasonably set problem, and according to the students' actual situation design problems, issued the students before class. When teaching class, teachers organize students make reasonable discussion and analysis, and encourage group discussion, finally teachers make guidance and answers on the discussion results and students' deficiency.

\subsection{The application research of PBL teaching}

PBL teaching in practical application, it need let the proposition of the problem on the basic position, the classroom knowledge architecture around proposed issues are established. In the process of, not constrained by a particular method, encourage students to do the practice of various methods, improve the students' independent problem-solving ability. In group discussions, improve the social coordination ability, actively cooperate with classroom learning. For learning evaluation, it should be think seriously, in order to improve the learning ability.

\section{Integrated analyses on networked learning and PBL teaching}

Along with the network popularization in higher teaching environment, through the Internet platform, combine the PBL teaching mode and networked learning, can reduce the limitations of time and place and other various factors, and can improve the integrated ability of education resources, optimize the education process, improve students' learning effect.

In networked learning, PBL teaching is organically integrated. By using network teaching resources; carry out group discussion, according to the students' practical ability and characteristics 
grouped, optimize grouping efficiency, and improve the effect of students cooperatively solving the problem. At the same time, teachers can teach and answer questions online in the network, through various channels and student discuss and analyze, guide students' learning. The networked learning combined with PBL teaching, which is beneficial to reduce teachers' input, due to the unlimited time and place characteristics of networked learning, using the computer to operate, which can greatly save the teacher's human resources, the conditions needed to complete the teaching task is reduced gradually, and it can achieve better teaching effect.

In the network environment, the teacher make proposition of PBL teaching problem in teaching platform, and students are grouped. After students obtain problem, they carry on grouping research and find information. Between students and students, they can use the network to efficiently collaborate and communicate. After completing preparation before class, teachers and students do online communication, under the teacher's guidance and supervision, the students discuss and put forward research achievements, and guidance and evaluation shall be made by teachers. Teachers constantly update and classify network learning resources, cause the student to obtain the latest scientific teaching information. After class, the teacher carry out evaluation work, evaluate students' various indicators ability and the completion effect in the learning, give precise effect, it is advantageous for the personalized guidance to students.

\section{Conclusion}

At present, the computer network technology continues to advance; the application of network technology has been the general trend in the education field. The networked teaching integrated with PBL teaching mode organically, which can improve the students' learning efficiency; increase students' learning interest, it has great significance to improve the students' learning ability, problem-solving and analysis ability. In addition, because of special implement way of the PBL teaching mode, it will has improved a lot on students' expression ability, social communication ability, organization and coordination ability and so on, it has important significance for the students carry on good work in the future.

\section{References}

[1] Li Yu, Mi Can: The integrated mode design of PBL teaching and networked learning [J], Journal of Chinese higher medical education, 2006, (11).

[2] Gao Lingfeng: The thinking of networked learning under information environment [J], Journal of Zibo Normal College, 2006, (03).

[3] Liu Hengzhong: Efficient networked learning idea, path and strategy [J], China Educational Technology, 2012, (10).

[4] Liu Hongxia, Pan Hong, Yang Lijuan, Diao Huiling: The innovation and application of PBL in higher medical colleges and universities teaching [J], Value engineering, 2007, (5). 